\title{
The genetic control of pheromone production and response in the pine engraver beetle Ips pini
}

\author{
BARBARA J. HAGER* \& STEPHEN A. TEALE \\ State University of New York, College of Environmental Science and Forestry, 1 Forestry Drive, Syracuse, New York \\ 13210, U.S.A.
}

\begin{abstract}
An understanding of the genetic coordination of signal and response in communication systems is an elusive quest in many organisms. Two hypotheses currently exist to explain the mechanism of coordination and its evolution: (1) signal-response systems are a result of pleiotropic effects of a gene or genes controlling the neural network underlying both or, (2) independent genes produce the signal and response and selection acts similarly on the traits. In this study, we tested the hypothesis that independently assorting genes control the production of, and response to, a sex pheromone in the pine engraver beetle, Ips pini. We measured the genetic correlation of production and response in sons from two situations: wild-caught pairs where there was some level of assortative mating and after five generations of forced 'no choice' mating. If production and response are a result of pleiotropy then there should be no breakdown in the genetic correlation of the two traits under the 'no choice' mating. Both pheromone production by males and the response to it by males and females are highly heritable. Male response appears to be genetically unlinked to pheromone production; therefore it is likely that the traits are not a result of pleiotropy. Instead, assortative mating may maintain the phenotypic correlation between the pheromone blend produced and the blend to which that individual responds.
\end{abstract}

Keywords: communication systems, heritability, Ips pini, ipsdienol, pheromones.

\section{Introduction}

The use of sex pheromones to attract mates is a common signal-response communication system in insects, particularly in the orders Lepidoptera and Coleoptera. In communication systems, the sender must produce a signal that the receiver recognizes; thus some sort of genetic coordination of signal and response between individuals should occur. Two opposing hypotheses have been proposed to explain the evolution and maintenance of such communication among conspecifics. Under the genetic coupling hypothesis, there is a linkage or sharing of common elements for signal production and recognition (Alexander, 1962). Any similarity between production and response is a result of pleiotropic effects of genes influencing the neural network controlling

*Correspondence: Department of Biology, University of Richmond, Richmond, Virginia 23173. both traits (Hoy, 1974). Alternatively, the coevolution hypothesis states that independent genes produce the signal and the response and the coordination of sender and receiver mechanisms results from selection pressures acting similarly on the traits (von Helverson \& von Helverson, 1975a,b; Elsner \& Popov, 1978). Under either hypothesis, a quantitative genetics analysis of the traits might reveal a phenotypic or genetic correlation; Boake (1991) views the genetic coupling hypothesis as a special case of genetic correlation whereby the correlation is a result of pleiotropy rather than selection, linkage disequilibrium, or other evolutionary forces. Thus genetic coupling is an end-product of strong selection over many generations favouring tight coordination of signal and response (Doherty \& Hoy, 1985).

Some of the controversy surrounding the extent to which genetic coupling or coevolution explains the correspondence between signal and response in sexual communication systems centres on the information obtained from interspecific and interstrain 
crosses, the most commonly used methods to examine communication systems (e.g. Butlin \& Ritchie, 1989; Boake, 1991; Charalambous et al., 1994). Hybridization studies must be taken at least to the $F_{2}$ or first backcross generations in order to have the potential to distinguish genetic coupling from coevolution (Doherty \& Hoy, 1985; Butlin \& Ritchie, 1989). With this as a caveat, two studies allow the distinction between the two hypotheses and both of these favour coevolution of sexual signals and preferences for Drosophila mojavensis and $D$. arizonensis (Zouros, 1981) and the European corn borer, Ostrinia nubilalis (Roelofs et al., 1987; Butlin \& Ritchie, 1989; Löfstedt et al., 1989).

Although hybrid crosses carried through several generations provide information about the genetic control of signals and responses, the techniques of quantitative genetics allow us to examine both the genetics of signal and response (the heritability of the two traits) and the genetic correlation between them within a population (Falconer, 1981). Like short-term hybrid studies, the determination of a genetic correlation does not allow us to distinguish between pleiotropy or close linkage of the traits unless we can break up the genetic correlation with further crosses. Five to ten generations of random mating destroy the correlation if the genes for the traits are separate but loosely to tightly linked (Crow, 1986). If the genetic correlation remains the same, then the traits most likely are caused by the same gene or set of genes.

In New York populations of Ips pini, males produce a pheromone composed of ipsdienol (2-methyl-6-methylene-2,7-octadien-4-ol) (Birch et al., 1980; Lanier et al., 1980) and lanierone (4,4,6-trimethyl-2-hydroxy-2,5-cyclohexadiene-12-one) (Teale et al., 1991) in a ratio of 100:1 (ipsdienol:lanierone). The pheromone attracts conspecifics when it is released in the faecal pellets upon initiation of a nuptial gallery in a suitable host tree. It functions as both a sexually selected signal and a host location signal. Ipsdienol is a chiral compound; an individual beetle produces a mixture of the two enantiomers (optical isomers), (R)-(-) and (S)-(+) ipsdienol. Chirality of the ipsdienol varies geographically. Populations in western North America produce an ipsdienol blend of mostly the $(\mathrm{R})-(-)$ enantiomer (Birch et al., 1980; Miller et al., 1989; Seybold et al., 1995), whereas New York populations produce the enantiomers in equal proportions (Lanier et al., 1980; Miller et al., 1989; Teale \& Lanier, 1991). Female response to enantiomeric blends varies accordingly (Birch et al., 1980; Mustaparta et al. 1985; Teale \& Lanier, 1991).
Within an I. pini population the enantiomeric blend produced by the male and the female's average response ('preference') in an olfactometer are correlated for wild-caught mated pairs (Teale $e t$ al. 1994). Assortative mating can lead to linkage disequilibrium of enantiomeric production and response (O'Donald, 1980; Lande, 1981; Kirkpatrick, 1982; Heisler, 1984) and consequently to the observation of phenotypic and genetic correlations of these traits in the progeny. Because these correlations can result from a variety of causes other than assortative mating, we used quantitative genetic analyses to examine the extent of genetic control and linkage of pheromone production and response. We tested the hypothesis that in $I$. pini, independently segregating genetic factors control enantiomeric preference and production by measuring the genetic correlation of production and response in sons from two types of matings: assortative mating by wild-caught pairs and forced 'random' or 'no choice' mating. If enantiomeric production and response result from pleiotropy or tight linkage then after five generations of forced random mating, the genetic correlation of the traits should be maintained. However, if the traits are slightly linked or unlinked, five generations is the minimum amount of time necessary to disrupt linkage disequilibrium (Crow, 1986) and reduce the genetic correlation to zero.

\section{Materials and methods}

From 1991 to 1993, we collected beetles near Cuyler Hill, NY, $37 \mathrm{~km}$ southeast of Syracuse from early May until early October each year. We obtained mated pairs of beetles by using baited $0.5 \mathrm{~m}$ white pine (Pinus strobus) logs. The bait consisted of an open, $3.7 \mathrm{~mL}$ polyethylene vial (Olympic plastics) with a blend of $0.1 \mathrm{mg}$ of lanierone and $10 \mathrm{mg}$ of enantiomeric ipsdienol in pentane in one of the following compositions: 20 per cent $(\mathrm{R})-(-), 50$ per cent $(\mathrm{R})-(-)$ or 80 per cent $(\mathrm{R})-(-)$ ipsdienol. We removed the baits when the first males entered the log; only the subsequent pairs of beetles colonizing the logs were collected. We maintained a constant supply of fresh logs for colonization.

In the laboratory, both sexes of the mated pair were assayed for their enantiomeric blend responses. Beetles were left individually in damp Petri dishes for $24 \mathrm{hrs}$ (no food) before being tested. In an olfactometer, we presented beetles with eight different, $1 \mu \mathrm{g}$ doses of the enantiomers, representing a range of pheromone blends: 2 per cent, 16.5 per cent, 30 per cent, 43.5 per cent, 57 per cent, 70.5 
per cent, 84 per cent, and 97.5 per cent $(\mathrm{R})-(-)$ ipsdienol in pentane. Lanierone was added to each blend in a ratio of 1:100 (lanierone:ipsdienol). The olfactometer was constructed of seven $3 \mathrm{~mm}$ inner diameter nalgene Y-tubes in a sequentially bifurcating pattern with interconnecting pieces of glass tubing of the same i.d. (Hager \& Teale, 1994). For each assay (6-8 same-sex beetles), the placement of the baits was constant. All eight baits $(0.5 \times 2.5 \mathrm{~cm}$ pieces of filter paper impregnated with pheromone) were loaded with pheromone and attached to the olfactometer while the air flow was blocked. After the start of air flow, we allotted five minutes for its equalization in all arms of the tubing and for evaporation of the solvent. The charcoal-filtered air flowed through the apparatus at a rate of $80 \mathrm{~mL} / \mathrm{min}$ and upon exiting was removed by a vacuum pump. We discarded the baits after the assay ended and rearranged the spatial configuration of the enantiomeric blends for the next assay by twisting the Y-tube junctions. Each beetle was assayed five times in a day (with a $>15$ min recovery period between assays). The average of these assays is its 'response phenotype', i.e. its preference for a particular pheromone blend. We describe the rationale and more details of the experimental protocol elsewhere (Hager \& Teale, 1994; Teale et al., 1994).

We obtained the enantiomeric composition of the pheromone produced by males by individually aerating them on small $7 \mathrm{~mm}$ discs of white pine phloem for 48 hrs. The aeration device consisted of a vertical Teflon tube $(7 \mathrm{~mm}$. i.d.) with a glass plug in the bottom, phloem disks in the middle, and a Teflon seal at the top through which a smaller Teflon tube (3 mm) was inserted (Teale et al., 1994). Charcoalfiltered air was drawn through this assembly via a vacuum pump at a rate of $200 \mathrm{~mL} / \mathrm{min}$. The volatiles from the frass produced by the feeding beetles were carried to a pipette containing $0.5 \mathrm{~g}$ of the adsorbent Porapak-Q, a plastic polymer capable of collecting the volatiles. We extracted the pheromone using 200 $\mu \mathrm{L}$ of pentane and determined the enantiomeric composition of the ipsdienol by injecting a $1 \mu \mathrm{L}$ aliquot of each sample into a Hewlett-Packard gas chromatograph/mass spectrometer (model 5890 series II/ model 5971) equipped with a chiral GC column $(0.25 \mathrm{~mm}$ internal diameter $\times 30 \mathrm{~m})$ (Cyclodex-B, J \& W Scientific, Folsom, CA) that separates many terpene alcohol enantiomers. We set the mass spectrometer to selective ion monitoring mode $(\mathrm{M} / \mathrm{z}=85$, the base peak for ipsdienol) to eliminate host volatiles. The ratio of $(\mathrm{R})-(-)$ to $(\mathrm{S})-(+)$ ipsdienol is the ratio of their respective peak areas from the chromatogram.
We raised families on individual white pine slabs $(16.5 \mathrm{~cm} \mathrm{~L} \times 11.5 \mathrm{~cm} \mathrm{~W} \times 7 \mathrm{~cm} \mathrm{H})$ consisting of bark and sapwood; the slabs were sealed with hot paraffin on the ends and open wood face to retain moisture. After the phenotypic measurements, we placed a male in a $\log$ by coring a $7 \mathrm{~mm}$ hole through the bark and caging him in with a small piece of window screen. Two days later, after construction of the nuptial gallery, we placed the original female under the screening. Only rarely did the female not quickly join the excavating male. Each $\log$ was placed in a round plastic container, $20 \times 12.5 \mathrm{~cm}$, with two large screened openings for ventilation. The containers were put in a room with a constant temperature of $29.4^{\circ} \mathrm{C}$. After $21-28$ days (when the progeny started emerging), the logs were moved to individual emergence cans. At least 30 progeny were allowed to emerge before we chose offspring to assay for pheromone blend preference (sons and daughters) and pheromone blend production (sons). We chose younger progeny to ensure that they were the offspring of our crosses. Females store sperm from previous matings; it takes about $24 \mathrm{~h}$ for the sperm from later matings completely to replace earlier sperm (Lissemore, 1993). Thus the older progeny, from the earliest eggs laid by the female, may belong to a male from a previous mating.

Of the original 502 wild-caught pairs, we obtained measurable offspring from 236 families. The heritabilities of the two traits and the genetic correlation when pairs are allowed to assortatively mate were estimated after this one generation of assortative mating. This provides us with a measure of heritability and the genetic correlation of the traits in the wild population. The degree of assortative mating, obtained by measuring each of the mated pairs that were found in the field, was 0.23 $(n=502)$. Complete assortative mating would have had a value of 1 .

For the random ('forced') mating treatment, we collected beetles from the same wild population to initiate 400 separate lines (families) to undergo five generations of random matings. The beetles were collected in several ways: from logs on which they were walking, from a log baited with a $50: 50$ blend of ipsdienol, and from galleries that were just initiated. Every effort was made to ensure that a representative mixture of unrelated beetles was obtained from that population and that if a mated pair was collected, the mates were separated and paired forcibly with other individuals. In starting the random mating, the beetles were paired without consideration of the enantiomeric composition of the male's pheromone or female's preference. In the 
initial parental generation, every family was assigned a number. Using a random number generator in each generation to determine which families to cross, we crossed individuals of the surviving lines by placing a female in a male-initiated gallery following the same procedure for raising progeny given above; females did not 'choose' mates and forced, no-choice matings occurred in each generation. From each family only a single son and daughter were mated to individuals of other lines to create the next generation. After five generations we measured a male's phenotype and crossed the remaining 262 lines to obtain sons; we achieved 189 complete measurements for fathers and sons. Only males were measured here because we were interested in breaking up the correlation within an individual and males show both of the traits.

We calculated heritability estimates for the enantiomeric composition of male ipsdienol production and response preference for both treatments. We also calculated female response preference heritability from the field-mated pairs because we were interested in determining the heritability of female response in the field. To estimate heritability under assortative mating, it is necessary to account for the influence assortative mating has on the additive genetic variance. In our system, because both sexes respond to the pheromone, the phenotypic resemblance between parents is based on the preference trait for the enantiomeric blends of ipsdienol.

The estimation of heritability based on parent/ offspring resemblance is given by:

$h^{2}=2\left(b_{\mathrm{op}}\right) /(1+r)$

where $h^{2}$ is heritability, $b_{\text {op }}$ is the regression slope between parent and offspring and $r$ is the phenotypic correlation between the parents (Falconer, 1981). In randomly mating populations the phenotypic correlation for any single trait between parents is effectively zero. In contrast, assortative mating for a trait implies a positive correlation between the parents. The estimate of heritability obtained by assortative mating is considered to be more precise than that of random mating because it reduces the standard error by decreasing the sampling variance in the regression (Reeve, 1961; Falconer, 1981). However, if the relationship of the trait between parent and offspring is nonlinear, then additive genetic variance may be overestimated (Gimelfarb, 1985, 1986).

The genetic correlation of production and response is obtained by the equation:
$r_{\mathrm{A}}=\frac{C O V_{P R}}{\sqrt{C O V_{P P} C O V_{R R}}}$,

where $C O V_{P R}$ is the cross-covariance of the parents' enantiomer production $(P)$ and the value of response preference $(R)$ in the offspring and $C O V_{P P}$ and $C O V_{R R}$ are the offspring-parent covariances of each character separately (Falconer, 1981). To obtain the cross-covariance it is necessary to calculate the covariance between parent and offspring for the two traits. Therefore:

$r_{\mathrm{A}}=\frac{C O V_{P 1 R 2}+C O V_{P 2 R 1}}{2\left(C O V_{P 1 P 2} C O V_{R 1 R 2}\right)}$,

where $C O V_{P 1 R 2}$ is the product of the variance in production in fathers and response in sons and $C O V_{P 2 R 1}$ is the reverse - the product of the variance of response in fathers and the production in sons (Becker, 1984). The standard error of the genetic correlation was calculated by using the estimation formula (Becker, 1984):

$\mathrm{SE}=\frac{1-r_{\mathrm{G}}^{2}}{\sqrt{2}} \times \frac{\left[\mathrm{SE}\left(h_{1}^{2}\right) \times \mathrm{SE}\left(h_{2}^{2}\right)\right]}{\sqrt{\left.\left(h_{1}^{2}\right) \times\left(h_{2}^{2}\right)\right]}}$

where $r_{\mathrm{G}}$ is the genetic correlation estimate, $h_{1}^{2}$ is the heritability of production and $h_{2}^{2}$ is the heritability of response and the standard errors of the heritabilities are estimated from the regression analyses.

We tested whether the phenotypic correlation coefficients were significantly different from zero using traditional correlation statistics and the Fisher transformation with its estimates of the standard error (Zar, 1984). In contrast, for the genetic correlation we used the standard errors and confidence intervals estimated via Becker's methodology (1984) because the underlying distribution of genetic correlations remains unknown and the more traditional statistical techniques require assumptions that may not be met. Significant regression slopes result in heritabilities that are statistically different from zero, so no further analyses were performed.

\section{Results}

Heritability estimates are high for the enantiomeric composition of ipsdienol produced by males whether the males are sons of wild-mated (assortative pairs) or sons of families that had undergone five generations of forced, no-choice matings (Table 1). The heritability of male response based on sire-son regression is lower than that for production. Female 
response shows moderate levels of heritability (Table 2).

The phenotypic correlation between enantiomeric production and response of males is reduced to zero after five generations of forced 'random' mating (Table 3). The genetic correlation does not differ from zero in the wild population or in the laboratory population although there is a trend towards a change in the sign of the correlation from nonrandom to random mating; these two correlations are significantly different from each other (Fisher's transformation: $z=4.96, P<0.001)$.

\section{Discussion}

There is strong heritability for both the production of, and response to, the enantiomeric composition of ipsdienol in Ips pini. These two traits (production and response) appear to be controlled by independently segregating genes because the estimate of the

Table 1 Heritability estimates for ipsdienol enantiomeric response and production in male Ips pini based on parent (sire)-offspring regression using sons of field-caught mated pairs (mild assortative mating) and for sons of laboratory-reared lines after five generations of forced, no-choice mating

\begin{tabular}{lcclcc}
\hline & \multicolumn{2}{c}{ Assortative mating } & & \multicolumn{2}{c}{ Random mating } \\
\cline { 2 - 3 } \cline { 5 - 6 } Character & $\begin{array}{c}\text { Regression } \\
\text { coefficient } \pm \mathrm{SE}\end{array}$ & $\begin{array}{c}\text { Heritability } \\
\text { estimate } \pm \mathrm{SE}\end{array}$ & & $\begin{array}{c}\text { Regression } \\
\text { coefficient } \pm \mathrm{SE}\end{array}$ & $\begin{array}{c}\text { Heritability } \\
\text { estimate } \pm \mathrm{SE}\end{array}$ \\
\hline $\begin{array}{c}\text { Male } \\
\text { production }\end{array}$ & $\begin{array}{c}0.537 \pm 0.055^{* *} \\
(235)\end{array}$ & $0.951 \pm 0.111$ & & $0.411 \pm 0.067^{* *}$ & $0.823 \pm 0.133$ \\
$\begin{array}{c}\text { Male } \\
\text { response }\end{array}$ & $\begin{array}{c}0.257 \pm 0.065^{* *} \\
(226)\end{array}$ & $0.455 \pm 0.129$ & & $\begin{array}{c}0.148 \pm 0.072^{*} \\
(189)\end{array}$ & $0.296 \pm 0.144$ \\
\hline
\end{tabular}

Numbers in parentheses are the sample sizes.

Significant at: ${ }^{*} P<0.05$ and ${ }^{*} P<0.0001$.

Table 2 Slopes of parent-offspring regression for Ips pini, broken down by sex, for response phenotype of enantiomeric preference of ipsdienol after one generation of naturally occurring assortative mating. Note that the estimate of heritability is not quite twice the regression coefficient because it is necessary to adjust for the correlation of response preference in the parents of $r=0.13$

\begin{tabular}{|c|c|c|c|c|}
\hline \multirow{2}{*}{$\begin{array}{l}\text { Character and } \\
\text { regression type }\end{array}$} & \multirow{2}{*}{$\begin{array}{c}\text { Regression } \\
\text { coefficient } \pm \mathrm{SE}\end{array}$} & \multirow{2}{*}{$\begin{array}{c}\text { Heritability } \\
\text { estimate } \pm \text { SE }\end{array}$} & \multicolumn{2}{|c|}{$\begin{array}{l}\text { Mean (and variance) } \\
\text { of } \%(-) \text { ips dienol }\end{array}$} \\
\hline & & & Parent & Offspring \\
\hline Father-son & $\begin{array}{c}0.257 \pm 0.0646^{* * *} \\
(n=226)\end{array}$ & $0.455 \pm 0.129$ & $47.38(174)$ & $47.32(189)$ \\
\hline Father-daughter & $\begin{array}{c}0.193 \pm 0.0677^{*} \\
(n=212)\end{array}$ & $0.341 \pm 0.135$ & $48.17(171)$ & $48.73(158)$ \\
\hline Mother-son & $\begin{array}{c}0.219 \pm 0.0641^{* *} \\
(n=234)\end{array}$ & $0.388 \pm 0.128$ & $47.47(171)$ & $47.32(189)$ \\
\hline Mother-daughter & $\begin{array}{c}0.152 \pm 0.0671^{*} \\
(n=219)\end{array}$ & $0.269 \pm 0.134$ & $46.88(182)$ & $48.63(167)$ \\
\hline Midparent-son & $\begin{array}{c}0.306 \pm 0.0685^{* * *} \\
(n=195)\end{array}$ & $0.541 \pm 0.137$ & $47.51(100)$ & $47.53(196)$ \\
\hline Midparent-daughter & $\begin{array}{c}0.234 \pm 0.070^{* *} \\
(n=195)\end{array}$ & $0.414 \pm 0.140$ & $47.51(100)$ & $48.79(165)$ \\
\hline Midparent-offspring & $\begin{array}{c}0.354 \pm 0.0674^{* * *} \\
(n=195)\end{array}$ & $0.627 \pm 0.135$ & $47.51(100)$ & $48.13(109)$ \\
\hline
\end{tabular}

Significantly different from zero at: ${ }^{*} P<0.05,{ }^{* *} P<0.001,{ }^{* * *} P<0.0001$. 
Table 3 Phenotypic $\left(r_{\mathrm{P}}\right)$ and genetic $\left(r_{G}\right)$ correlations $( \pm \mathrm{SE})$ of ipsdienol enantiomeric response and production from sons of Ips pini calculated for sons from the naturally occurring assortatively mated field parents and for sons from families that had undergone five generations of forced, no-choice matings

\begin{tabular}{|c|c|c|c|c|}
\hline \multirow{2}{*}{$\begin{array}{l}\text { Correlation } \\
\text { type }\end{array}$} & \multicolumn{2}{|c|}{ Assortative mating } & \multicolumn{2}{|c|}{ Random mating } \\
\hline & Correlation & Confidence limits & Correlation & Confidence limits \\
\hline$r_{\mathrm{P}}$ & $\begin{array}{c}0.165 \pm 0.065 \\
n=226\end{array}$ & $\begin{array}{c}0.038<r<0.292 \\
(P<0.013)\end{array}$ & $\begin{array}{c}-0.008+0.074 \\
n=189\end{array}$ & $\begin{array}{c}-0.014<r<0.152 \\
(P<0.91)\end{array}$ \\
\hline$r_{\mathrm{G}}$ & $\begin{array}{c}0.207 \pm 0.216 \\
n=226\end{array}$ & $\begin{array}{c}-0.208<r<0.559 \\
(P<0.75)\end{array}$ & $\begin{array}{c}-0.272 \pm 0.367 \\
n=189\end{array}$ & $\begin{array}{c}-0.761<r<0.41 \\
(P<0.75)\end{array}$ \\
\hline
\end{tabular}

$P$-values for test of significance for $r=0$, using Fisher transformations of $r$ in the analysis (Zar, 1984).

genetic correlation under either mating situation is not significantly different from zero. Under these circumstances, pleiotropy cannot be a factor in the coevolution of the enantiomeric blend of ipsdienol and the response to certain blends. This independence of the genes controlling pheromone blend production and response corresponds to the findings for the European corn borer (Löfstedt et al., 1989); the order Coleoptera is the second major taxon using pheromone communication systems to lack linkage of signal and preference traits.

Many of the sexual selection models that address the evolution of male traits and female preferences (e.g. good genes, Fisherian runaway) require that a genetic correlation underlie the observation of a phenotypic correlation between the signal and the response in order for the traits to continue to evolve. Disagreement abounds over the strength of the genetic correlation necessary for coevolution; theoretically the correlation can be very weak (Barton \& Turelli, 1991). Previous quantitative genetics studies that have sought to demonstrate a genetic correlation between the male trait and female preference use selected lines on the male trait and look for correlated responses on the female trait (e.g. most recently, Wilkinson \& Reillo, 1984; Houde 1992, 1994; Bakker, 1993; Breden \& Hornaday, 1994). In our system, we treat male response as equivalent to female preference (brothers have the same response phenotypes as sisters); the heritabilities based on father-son and father-daughter regressions are equivalent (Table 3 ). Thus we can estimate the genetic correlation of the traits within the individual male.

The results of studies examining the genetic correlation of sexually selected traits are mixed. Even within the same organism, correlated responses of female preference to selection on the male trait are seen (Houde, 1992) at the same time when no correlated response could be found (Breden \& Hornaday, 1994). These contradictory findings could be an artifactual result of using different populations (Houde, 1993) or different mating regimes (Pomiankowski \& Sheridan, 1994). Houde (1992) allowed females to choose their mates whereas Breden \& Hornaday (1994) did not.

The coevolution of traits can result from a number of factors, including linkage disequilibrium, drift and nonrandom mating. Together with the studies mentioned above, this has important implications for the results reported here. In the New York population of $I$. pini, females assortatively mate with males (Teale et al., 1994). Female choice is repeatable (Hager \& Teale, 1994) and heritable. Nevertheless, the degree to which assortative mating occurs throughout the flight season varies. Over the three years of the study, the phenotypic correlation between male blend production and female blend preference is $-0.038 \pm 0.09(P<0.67)$ in the spring when the individuals who overwintered begin to breed whereas it is $0.26 \pm 0.08(P<0.001)$ in the summer when the offspring and recolonizing individuals are mating (unpub. data). Reasons for the lack of assortative mating in the spring generation are speculative at best. Males in the laboratory produce almost pure (S)-(+)-ipsdienol immediately after emerging from diapause but produce more 'normal' values after feeding for about a week $(\bar{x}=94.8 \pm 5.6$ vs. $63.2 \pm 8.7$ per cent (S)-( + ) ipsdienol, $n=13)$. This may be a result of differential activation of enzymatic pathways. Alternatively, the probability of late frosts and its associated mortality may constrain the female (and males) into quickly choosing a host. In either case, choosy females may be at a selective disadvantage in spring.

Regardless of why this seasonal change in the 
degree of assortative mating occurs, there are serious genetic consequences. As noted earlier, it takes several generations to build up a genetic correlation between initially unlinked traits or to break down linkage disequilibrium (Crow, 1986). If I. pini is undergoing 'episodes of selection' where natural selection for survival in the spring outweighs sexual selection and the converse is true for the summer, then a genetic correlation between male pheromone blend and female preference may never be achieved. Other factors, such as predation risk, can influence female choice (Breden \& Stoner, 1987). Parasites and predators of $I$. pini show enantiomeric specificity (Raffa \& Klepzig, 1989; Herms et al., 1991).

In conclusion, both the male trait, enantiomeric blend of ipsdienol, and the female trait, enantiomeric blend specificity, show high heritability. Male response specificity is also strongly heritable and appears to be genetically unlinked to the enantiomeric blend that the male produces. Consequently, if male blend preference and female blend preference are caused by the same genes, then female blend preference is also unlinked with blend production. It appears that episodes of assortative and random mating both contribute to, and break down, the phenotypic correlation observed within males for these traits. The results concerning the genetic correlation must be interpreted with some caution. Small sample sizes cause a loss in the ability to obtain a significant estimate of the genetic correlation between traits (Falconer, 1981; Becker, 1984). Thus with larger samples, the genetic correlations may be significantly different from zero. Additionally, the examination of the genetic correlation between male production and female response after each generation of random mating would have provided us with more information about the role of linkage disequilibrium in maintaining the observed phenotypic correlation of the traits. If linkage disequilibrium is halved every generation, then this provides more compelling evidence that the genes are unlinked. At the very least, the sample size for estimating the genetic correlation would have been greater at that time. Unfortunately, this was not logistically feasible in this study.

\section{Acknowledgments}

We thank Holly Zgoda for her invaluable technical assistance. Many thanks go to the anonymous reviewers whose comments vastly improved the final manuscript version. Research was funded by USDACSRS grant no. 91-37302-62131 (S.A.T.) and by the 'William M. Shields fund' (B.J.H.).

\section{References}

ALEXANDER, R. D. 1962. Evolutionary change in cricket acoustical communication. Evolution, 16, 443-467.

BAKKER, T. C. M. 1993. Positive genetic correlation between female preference and preferred male ornament in sticklebacks. Nature, 363, 255-257.

BARTON, N. H. AND TURElli, M.. 1991. Natural and sexual selection on many loci. Genetics, 127, 229-255.

BECKer, w. A. 1984. A Manual of Quantitative Genetics. Academic Enterprises, Pullman, Washington, DC.

BIRCH, M. C., LIGHT, D. M., WOOD, D. L., BROWNE, L. E., SIlverstein, R. M., Bergot, B. J. ET AL. 1980. Pheromonal attraction and allomonal interruption of Ips pini in California by the two enantiomers of ipsdienol. $J$. Chem. Ecol., 6, 703-717.

BOAKE, C. R. B. 1991. Coevolution of senders and receivers of sexual signals: genetic coupling and genetic correlations. Trends Ecol. Evol., 6, 225-227.

BREDEN, F. AND HORNADAY, K. 1994. A test of indirect models of sexual selection in the Trinidad guppy. Heredity, 73, 831-833.

BREDEN, F. AND STONER, G. 1987. Male predation risk determines female choice in the guppy (Poecilia reticulata). Nature, 329, 831-833.

BUTLIN, R. K. AND RITCHIE, M. G. 1989. Genetic coupling in mate recognition systems: what is the evidence? Biol. J. Linn. Soc., 37, 237-246.

Charalambous, M, BUTLin, R. K. AND hewitt, G. M. 1994. Genetic variation in male song and female preference in the grasshopper Chorthippus brunneus (Orthoptera: Acrididae). Anim. Behav., 47, 399-411.

Crow, J. F. 1986. Basic Concepts in Population, Quantitative and Evolutionary Genetics. W.H. Freeman, New York.

DOHERTY, J. AND HOY, R. 1985. Communication in insects. III. The auditory behavior of crickets: some views of genetic coupling, song recognition, and predator detection. Q. Rev. Biol., 60, 457-472.

ELSNER, N. AND POPOV, A. V. 1978. Neuroethology of acoustic communication. Adv. Insect Physiol., 13, 229-335.

FALCONER, D. S. 1981. Introduction to Quantitative Genetics, 2nd edn. Longman, Essex.

GIMELFARB, A. 1985. Is offspring-midparent regression affected by assortative mating of parents? Genet. Res., 47, 71-75.

GIMELFARB, A. 1986. Offspring-parent genotypic regression: how linear is it? Biometrics, 42, 67-71.

HAGER, B. J. AND TEALE, S. A. 1994. Repeatability of female response to ipsdienol enantiomeric mixtures by the pine engraver, Ips pini. J. Chem. Ecol., 20, 2611-2622.

HEISLER, 1. L. 1984. A quantitative genetic model for the origin of mating preferences. Evolution, 38, 1283-1295.

VON HELVERSON, D. AND VON HELVERSON, O. 1975a. Verhaltensgenetische unterschangen am akustichen Kommunkationsystem der Feldheuschrecken (Orthoptera, Acrididae) I. Der Sang von Arbastarden zwischen 
Chorthippus biguttulus und Ch. mollis. J. Comp. Physiol., 104, 273-299.

VON HELVERSON, D. AND VON HELVERSON, O. $1975 \mathrm{~b}$. Verhaltensgenetische unterschangen am akustichen Kommunkationsystem der Feldheuschrecken (Orthoptera, Acrididae) II. Das Lautschema von Arbastarden zwischen Chorthippus biguttulus und Ch. mollis. J. Comp. Physiol., 104, 301-323.

HERMS, D. A., HAACK, R. A. AND AYERS, B. D. 1991. Variation in semiochemical-mediated prey-predator interaction: Ips pini (Scolytidae) and Thanasimus dubius (Cleridae). J. Chem. Ecol., 17, 515-524.

HOUDE, A. 1992. Sex-linked heritability of a sexually selected character in a natural population of Poecilia reticulata (Pisces: Poeciliidae) (guppies). Heredity, 69, 229-235.

HOUDE, A. 1993. Evolution by sexual selection: what can population comparisons tell us? Am. Nat., 141, 796-803.

HOUDE, A. Е. 1994. Effect of artificial selection on male colour patterns on mating preference of female guppies. Proc. R. Soc. B., 256, 125-130.

HOY, R. 1974. Genetic control of acoustic behavior in crickets. Am. Zool., 14, 1067-1080.

KIRKPATRICK, M. 1982. Sexual selection and the evolution of female choice. Evolution, 36, 1-12.

LANDE, R. 1981. Models of speciation by sexual selection on polygenic traits. Proc. Natl. Acad. Sci. U.S.A., 78, $3721-3725$.

LANiER, G. N., Classon, A., STEWART, T., PISTON, J. AND SILVERSTEIN, R. M. 1980. Ips pini: the basis for interpopulational differences in pheromone biology. $J$. Chem. Ecol., 6, 677-687.

LISSEMORE, F. 1993. Sources of Variation in Male Mating Success and the Function of Frass-Clearing by Males in the Pine Engraver Beetle, Ips pini (Scolytidae). Ph.D. Thesis, Syracuse University, New York.

LÖFSTEDT, C., HANSSON, B. S., ROELOFS, W. AND BENGTSSON, B. o. 1989. No linkage between genes controlling female pheromone production and male pheromone response in the European corn borer, Ostrinia nubilalis Jubner (Lepidoptera: Pyralidae). Genetics, 123, 553-556.

MILLER, D. R., BORDEN, J. H. AND SLESSOR, K. N. 1989. Inter- and intrapopulation variation of the pheromone, ipsdienol produced by male pine engravers, Ips pini (Say) (Coleoptera: Scolytidae). J. Chem. Ecol., 15, 233-247.

MUSTAPARTA, H., TOMMERAS, B. A. AND LANIER, G. N. 1985. Pheromone receptor cell specificity in interpopulational hybrids of Ips pini (Coleoptera: Scolytidae). J. Chem. Ecol., 11, 999-1007.

o'Donald, P. 1980. Genetic Models of Sexual Selection. Cambridge University Press, Cambridge.

POMIANKOWSKI, A. AND SHERIDAN, L. 1994. Linked sexiness and choosiness. Trends Ecol. Evol., 9, 242-244.

RAFFA, K. F. AND KLEPZIG, K. D. 1989. Chiral escape of bark beetles from predators responding to a bark beetle pheromone. Oecologia, 80, 566-569.

REEVE, E. C. R. 1961. A note on non-random mating in progeny tests. Genet. Res., 2, 195-203.

ROElOFS, W., GlOER, T., TANG, X., SRENG, I., ROBbins, P., ECKENRODE, C. ET AL. 1987. Sex pheromone production and perception in European corn borer moths is determined by both autosomal and sex-linked genes. Proc. Natl. Acad. Sci. U.S.A., 84, 7585-7589.

SEYBOLD, S. J., OHTSUKA, T., WOOD, D. L. AND KUBO, I. 1995. The enantiomeric composition of ipsdienol: a chemotaxonomic character for North American population of Ips spp. in the pini subgeneric group (Coleoptera: Scolytidae). J. Chem. Ecol., 21, 995-1016.

TEALE, S. A., HAGER, B. J. AND WEBSTER, F. X. 1994. Pheromone-based assortative mating in a bark beetle. Anim. Behav., 48, 569-578.

TEALE, S. A. AND LANIER, G. N. 1991. Seasonal variability in response of Ips pini (Coleoptera: Scolytidae) to ipsdienol in New York. J. Chem. Ecol., 17, 1145-1158.

TEALE, S. A., WEBSTER, F. X., ZHANG, A. AND LANIER, G. N. 1991. Lanierone: a new pheromone component from Ips pini (Coleoptera: Scolytidae) in New York. J. Chem. Ecol., 17, 1159-1176.

WILKINSON, G. S. AND REILlO, P. R. 1984. Female choice response to artificial selection on an exaggerated male trait in a stalk-eyed fly. Proc. R. Soc B., 255, 1-6.

ZAR, J. J. 1984. Biostatistical Analysis. Prentice Hall, Englewood, NJ.

zouros, E. 1981. The chromosomal basis of sexual isolation in two sibling species of Drosophila: $D$. arizonensis and $D$. mojavensis. Genetics, 97, 703-718. 